\title{
Renew, reflect, rejoice Immersion to the rescue
}

$\mathbf{F}_{\mathrm{n}}$ eel burned out from teaching the same monotonous one-shot library instruction sessions? Worry that all of your colleagues are always creating dynamic lesson plans, while you're stuck using the same one? Forget the last time you even thought about why you're teaching?

As library instructors, we've all felt this way. As the pressures and demands on teaching librarians grow, we believe the need for Immersion is more essential than ever. Many, if not most, librarians receive little or no formal training focused on instruction, but Immersion can help address this critical gap and pave the way to more thoughtful library instruction.

Immersion is ACRL's intensive training program for librarians interested in teaching. During this weeklong experience, instruction librarians gain knowledge of pedagogy and learn practical strategies to try out in the classroom. Immersion is a reflective, active, and collaborative experience, but for it to be truly effective, everyone needs to participate and take some risks. To make this easier, Immersion creates a safe environment conducive for risk-taking. With four unique tracks, Immersion imparts information literacy principles to participants. Tracks include Teacher, Intentional Teacher, Program, and Assessment. As former participants of Teacher and Intentional Teacher tracks, we'll discuss these two and explain not only why Immersion is important, but also why you should apply next year.

\section{Erin Davis's Immersion experience: Teacher Track}

Teacher Track is a rigorous program that provides intensive training for instruction librarians with minimal teaching experience. At Teacher
Track, you'll not only learn instructional design, learning theory, leadership, and authentic assessment framed in the context of information literacy, but you'll also meet other librarians who are new to teaching.

Each participant is assigned to a cohort consisting of ten to thirteen people, led by one of the Immersion faculty members. You will spend the majority of your time with these peoplethey become your family, your sounding board at Immersion. With this group, you will sculpt ideas out of clay and create "student" puppets out of paper bags. You'll experiment with a five-minute instructional scenario and receive constructive feedback that can be immediately applied to your teaching practice when you return home. Teacher Track offers a challenging yet supportive environment so that participants can enhance their natural talents as teachers and develop more authentic, confident, and integrated instructional practices.

For Davis, attending Immersion Teacher Track inspired the restructuring of her classes. She threw out lectures and adopted problembased learning scenarios to create lesson plans that encourage critical thinking from her students. Her classes are now student-centered sessions that incorporate clear learning objectives and assessments. Following Immersion, her cohort stayed in touch via Skype for several months and discussed instructional changes implemented after Immersion. Motivated by their success in the classroom, the cohort presented at the 2010 LOEX Annual Conference

Pamela N. Martin is reference and instruction librarian, e-mail: pamela.martin@usu.edu, Erin Davis is reference and instruction librarian at Merrill-Cazier Library at Utah State University, e-mail: erin.davis@usu.edu

๑ 2012 Pamela N. Martin and Erin Davis 
in Dearborn, Michigan, on problem-based learning and active learning strategies. This presentation included strategies for incorporating more problem-based learning into instruction and other ways to get librarians out from behind the podium. More recently, several members presented a poster session at the 2011 ALA Annual Conference, demonstrating how each brought Immersion principles back home to reinvigorate the teaching and learning of information literacy.

\section{Pam Martin's Immersion experience: Intentional Teacher Track}

Intentional Teacher Track is intended for those participants who have at least five years teaching experience. Since a major goal of the intentional teacher track is to encourage participants to craft a personal philosophy of instruction, you have more personal reflective time compared to other Immersion tracks.

The Intentional Teacher track provides time to reflect on yourself as a teacher-you learn what teaching styles work for you and what you might need to change in your instructional practice. By articulating your teaching philosophy, your objectives-as well as your strengths and weaknesses_-become clearer. You are basically codifying the "big picture" of instruction. You articulate not only your goals, but also what instruction and learning mean to you and what teaching methods you use and why.

The Intentional Teacher track is an introspective program that provides a safe space in which participants can, after years of teaching, finally slow down and (re)define themselves as teachers.

For Martin, Intentional Teacher Track provided the guidance she needed to craft a teaching philosophy and make meaningful changes in the classroom. By shaping a well-articulated teaching philosophy, she was able to tie lesson plans, teaching objectives and classroom tools to her "big picture."

For example, when writing her philosophy, she realized that, for her, information literacy must be taught holistically. So she abandoned checklists of evaluative criteria in favor of class discussions on source credibility. Now she presents source evaluation as a spectrum that ranges from low-quality sources to popular media sources to scholarly sources. The spectrum approach provides engaging classroom conversations and a much more realistic picture of the information environment than the checklist approach.

Intentional Teacher also helped her to realize she was struggling to make connections with students and fellow instructors, since she was only likely to see any given instructor's class one to four times per semester. To improve her teaching relationships, she experimented with student introductions and nametags and invited graduate student instructors to chat about library instruction over coffee.

\section{The bottom line}

Immersion reinvigorates librarians in their instruction practices. Whether librarians come with little teaching experience or years of standing up in front of the classroom, Immersion gives librarians the chance to renew themselves and network with instruction librarians from across the country. While it's inspiring simply to be around like-minded professionals who care deeply about information literacy, Immersion provides librarians that all-too-often rare opportunity to immerse themselves in pedagogy - to learn how to be a teacher rather than just a librarian who occasionally teaches.

At our university, we brought Immersion lessons back home to our library and not only applied them to our individual practices but also

\section{Immersion'13}

Applications are being accepted for Immersion ' 13 Teacher and Program Tracks. Embark on a path of teacher development and pedagogical inquiry in a community of practice for academic librarians devoted to collaborative learning, individual renewal, and instructional effectiveness. Immersion ' 13 will be held at Seattle University, July 28-August 2. Visit www. ala.org/acrl/immersionprogram for application materials and complete details. 
shared them with our fellow library instructors. We held a mini-workshop to impart some of the lessons we learned at Immersion. The workshop included group discussions about our roles as teachers, information on theories of learning, and inventories of participants' teaching styles. To spur our colleagues' creative thinking and get them out of their comfort zones, we asked them to express their teaching styles using modeling clay. We also asked them to consider their own teaching philosophies. By attending this workshop, our colleagues were able to learn valuable lessons from our Immersion experience and dedicate time to their own teaching practices. They offered positive feedback, and many asked for more information after the workshop. By leading this workshop, we not only shared lessons learned at Immersion, but we also developed ourselves as instructional leaders and innovators in our library.

Even after Immersion officially ended, we continued to reap the benefits of the program. Both of us made small but meaningful changes in our instruction practices and kept in contact with fellow attendees. Though Immersion can give you many exciting new ideas, we found that starting out small works best. If you implement too many changes at once, it can be overwhelming and often backfire. It's okay if you don't transform your teaching practice overnight. The best goals often take time to implement.

As the demand on instruction librarians continues to grow, Immersion offers the breathing space needed to reimagine and inform your instruction practice. It provides foundational information for novice instructors and reflective time for those with instruction experience. Immersion creates a safe space for librarians to thrive and take risks. As we are reaching out to increasing numbers of students in the classroom, our impact on those students needs to be more meaningful. It is not enough to reach greater numbers of the student body if we are not having a positive impact. With each track and each class of participating librarians, Immersion ensures we are truly benefiting the ever-growing number of library instruction students. $\boldsymbol{n}$

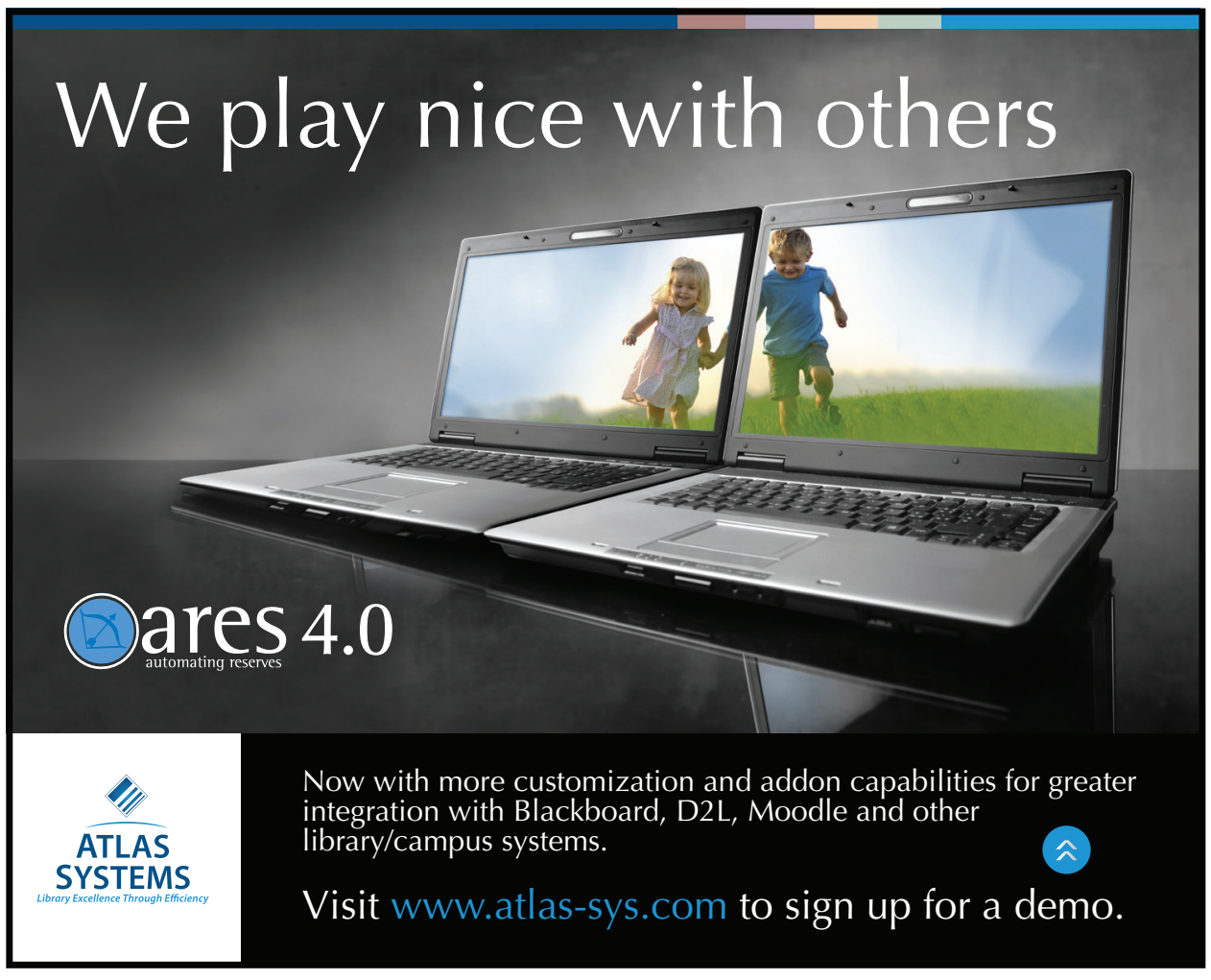

